\title{
In vivo exposure of susceptible and non-susceptible fish species to Myxobolus cerebralis actinospores reveals non-specific invasion behaviour
}

\author{
Dennis M. Kallert ${ }^{1}$, Edit Eszterbauer ${ }^{1,2}$, Daniel Grabner ${ }^{1}$, Mansour El-Matbouli $^{3,4, *}$ \\ ${ }^{1}$ Institute of Zoology, Fish Biology and Fish Diseases, University of Munich, Kaulbachstraße 37, 80539 Munich, Germany \\ ${ }^{2}$ Veterinary Medical Research Institute, Hungarian Academy of Sciences, Hungária krt 21, 1143 Budapest, Hungary \\ ${ }^{3}$ Clinic for Fish and Reptiles, Faculty of Veterinary Medicine, University of Munich, Kaulbachstraße 37, 80539 Munich, Germany \\ ${ }^{4}$ Present address: Fish Medicine and Stock Care, University of Veterinary Medicine, Vienna, Austria
}

\begin{abstract}
Due to controversial previous results, it has been unclear whether Myxobolus cerebralis (Myxosporea, Myxozoa) is able to specifically choose a salmonid host by selective attachment and penetration. Using a novel in vivo tracking assay that employs fluorescence staining of actinospore sporoplasms, we demonstrate a lack of host specificity of $M$. cerebralis actinospores during their initial invasion reactions. Fish were experimentally exposed to stained actinospores that could be detected as emitted sporoplasms in and on the fish integument of skin, gills and fins. There were no significant differences in the number of actively emerging sporoplasms found on epithelial surfaces of a susceptible and resistant strain of rainbow trout and common carp after experimental exposure. Numbers of parasite attachment rates to carp and trout gill tissue were also assessed using quantitative real-time PCR (qPCR). This method demonstrated that actinospore reactivity rate was not affected by the staining procedure. An even higher number of parasite stages was detected in carp than in trout gills. Subsequently, the ability of carp to lower the infection severity of susceptible rainbow trout by trapping the parasites under natural conditions was also investigated. Myxospore load was significantly reduced in hosts infected with actinospore samples that were preincubated with live carp. These results indicate the possibility of biological disturbance to the life cycle of the parasite in the wild by interceptor fish species as one measure to prevent whirling disease.
\end{abstract}

KEY WORDS: Myxozoa $\cdot$ Myxobolus cerebralis $\cdot$ Host specificity $\cdot$ Triactinomyxon $\cdot$ Rainbow trout Common carp $\cdot$ FDA staining $\cdot$ qPCR

\section{INTRODUCTION}

Actinospores are fragile, immotile waterborne transmission stages shed by oligochaetes that deliver a myxozoan parasite predominantly to a teleost secondary host. Successful transmission to fish hosts depends on coincidental contact and requires an instant attachment reaction to a putative host. Despite recent knowledge on the transmission mechanisms of actinospores (Kallert et al. 2007), interactions between myxozoan parasites and their fish hosts are still poorly understood (Hedrick \& El-Matbouli 2002). Although whirling disease induced by the cosmopolitan Myxobolus cerebralis has long been considered a severe disease of salmonid fish, it is not known whether the parasite uses host-specific stimuli (Gilbert \& Granath 2003). Kallert et al. (2005) demonstrated that $M$. cerebralis requires a combination of mechanical and mucus-derived chemical cues for extrusion of polar filaments followed by active emergence of an amoeboid sporoplasm that enters the epidermis of the host. 
Several other species of actinospores showed polar filament discharge or sporoplasm emission when they were offered mucus samples of non-susceptible hosts (Yokoyama et al. 1993, 1995, 2006, McGeorge et al. 1997, Özer \& Wootten 2002, Yokoyama \& Urawa 1997, Kallert \& El-Matbouli 2008). However, reports on pronounced host specificity during reactions to host stimuli among actinospores are scarce. Yokoyama et al. (2006) found specificity for sporoplasm release of Thelohanellus hovorkai towards carp mucus, which was in turn not preferred by echinactinomyxon-type spores when compared to muci of other fish during a survey by Özer \& Wootten (2002). Xiao \& Desser (2000) and Yokoyama et al. (1993) also detected divergent reaction rates when they observed actinospore responses to mucus of different fish species. El-Matbouli et al. (1999) hypothesised that the Myxobolus cerebralis actinospore has a high degree of host specificity for salmonids, as they could not detect penetrated stages in various cyprinid fish. These facts were challenged by results from in vitro assays showing clear reactions of $M$. cerebralis actinospores to mucus of non-susceptible fish species (Kallert et al. 2005). Thus it has remained controversial as to whether $M$. cerebralis shows attachment and attempts penetration of non-susceptible fish under in vivo conditions.

Quantitative real-time PCR (qPCR) methods have recently become a valuable tool to estimate parasite load and infection course of Myxobolus cerebralis (Cavender et al. 2004, Kelley et al. 2006). By using this technique, with an in vivo exposure approach and detection of invading stages on fish tissues and parasite abundance after sporogenesis, we intended to shed light on host-specificity during the invasion of $M$. cerebralis actinospores.

\section{MATERIALS AND METHODS}

Parasites and hosts. Rainbow trout Oncorhynchus mykiss fry were obtained from Troutlodge (TL strain) and Hofer Forellen (Oberndorf am Neckar; H strain). Common carp Cyprinus carpio egg clutches were obtained from a local Bavarian hatchery and raised under laboratory conditions with flow-through tap water. Carp and trout were $11 \mathrm{mo}(2.3$ to $2.5 \mathrm{~cm}$ total length) and $9.5 \mathrm{mo}$ ( 2.5 to $2.8 \mathrm{~cm}$ total length) old at the time of the exposure experiment, respectively. During the preincubation experiments, carp measured 3.0 to $3.4 \mathrm{~cm}$. Care was taken to choose fish specimens of all groups of approximately equal sizes for use in the experiments. Actinospores of Myxobolus cerebralis were obtained from established laboratory cultures of Tubifex tubifex in the Clinic for Fish and Reptiles in as described elsewhere (Kallert et al. 2007). Actinospores used in all experiments were up to $48 \mathrm{~h}$ old. After collection, actinospores were kept in $5 \mathrm{ml}$ flat-bottom glass jars until used.

Exposure to stained actinospores. The assay investigated host-invasion attempts by Myxobolus cerebralis actinospores when different fish species and trout strains are encountered. Actinospore solutions were stained with fluorescein-diacetate FDA $_{i} 1 \%$ volume $^{-1}$ of a 9-fold diluted aqueous working solution prepared from a stock solution of $5 \mathrm{mg} \mathrm{ml}^{-1}$ FDA in acetone) for $1 \mathrm{~h}$ in the dark at $8^{\circ} \mathrm{C}$ (see Markiw 1992). The spores were then washed in a tube with $20 \mu \mathrm{m}$ nylon mesh at 1 end with $20 \mathrm{ml}$ of tap water 3 times to remove excess fluorescent stain. After enumeration of 3 aliquots under a microscope, 6 portions of 8000 actinospores each were immersed in $100 \mathrm{ml}$ of tap water in $250 \mathrm{ml}$ beakers and were allowed to physiologically adapt to the conditions for $1 \mathrm{~h}$ at $15^{\circ} \mathrm{C}$. To these infection solutions, the respective fish was added and exposed for 3 min under constant movement of the water body keeping the fish in motion. Fish were then removed and killed by decapitation, and gill arches, pectoral fin and caudal fin of 1 side of the fish were taken along with mucus scrapings of 1 whole body side. All samples were immediately mounted on separate slide glasses with a drop of tap water and observed under a fluorescence microscope (Olympus BH-2-RFCA) to count emerged sporoplasms seen on or inside superficial tissues/mucus. Actinospores that were only attached but had not emerged from the actinosporean shells were excluded from the analysis. TL strain rainbow trout exposed to similarly stained filtrate water without actinospores served as controls. Additionally, 1 sample comprised of a mimic fish $(3 \mathrm{~cm}$ length, $1 \mathrm{~cm}$ height, $0.7 \mathrm{~cm}$ width with slimly peaking tail mimicking a caudal fin), cut out of $1.5 \%$ agar blocks, that was used in the same way as fish to detect unspecific reactions of the parasite. One whole side of the body and 'caudal fin' of the mimic fish were cut off with a scalpel for observation. Only 1 replicate could be processed with every species/sample per day. All steps were performed in the dark, and the respective fish species under investigation was unknown to the person enumerating the invading parasites.

To test whether dye staining had a negative influence on the capability of actinospores to invade a host, 8 size-matched rainbow trout (TL strain) were exposed to stained or unstained actinospores in the same way as described above. To assess accuracy of visual spore counting, 3 rainbow trout (TL strain) and 3 carp gill samples from different fish specimens were exposed to actinospores as described. All gill arches were excised after exposure, their wet weight was recorded, and samples were stored at $-20^{\circ} \mathrm{C}$ until subsequent molecular examination. The outcome from molecular estimation of spore numbers was used for comparison. 
Preincubation trial. This experiment was conducted to explore a hypothesised decoy effect of carp on waterborne Myxobolus cerebralis actinospores. We added 1500 actinospores to each of 18 glass beakers (1 l) filled with $700 \mathrm{ml}$ of tap water $\left(12^{\circ} \mathrm{C}\right)$. To 9 of these, 1 live carp was added for an incubation period of $70 \mathrm{~min}$. The contents of each beaker were then poured through a kitchen sieve into a new beaker, and 1 rainbow trout (TL strain) was added to each and left for $1 \mathrm{~h}$. Trout were then swilled with water and transferred to $50 \mathrm{l}$ flow-through aquaria. Fish were killed after $120 \mathrm{~d}$ post exposure and frozen at $-20^{\circ} \mathrm{C}$. Fish were thawed at $45^{\circ} \mathrm{C}$ in a water bath and defleshed, and minced skeletal elements of the heads were digested according to a modified protocol of Lorz \& Amandi (1994). Briefly, heads were treated with $20 \mathrm{ml}$ of a solution of pepsin $(0.5 \% \mathrm{w} / \mathrm{v}$, Sigma) in $0.5 \% \mathrm{HCl}$ and stirred simultaneously by a multiple magnetic stirrer (Variomag Multipoint HP 15) for $1.5 \mathrm{~h}$ at $37^{\circ} \mathrm{C}$. After centrifugation at $2500 \mathrm{rpm}$ for $10 \mathrm{~min}$, the pellet was resuspended in $8 \mathrm{ml}$ of a $0.05 \%$ solution of trypsin $(0.05 \%$ with $0.02 \%$ EDTA w/v in PBS, Biochrom AG) and shaken for $30 \mathrm{~min}$ at room temperature. Samples were then frozen at $-20^{\circ} \mathrm{C}$ after addition of $1 \% \mathrm{w} / \mathrm{v}$ of BSA (Sigma). For examination, the solution was filled to $10 \mathrm{ml}$ with tap water, vortexed and analysed microscopically in a Bürker chamber $\left(10 \times 4\right.$ of $0.04 \mathrm{~mm}^{2}$ squares sample $\mathrm{s}^{-1}$ ). The enumeration of myxospores was repeated twice, and none of the enumerators knew the sample identity.

Quantitative real-time PCR. To estimate the number of invading actinospores on tissue samples, a calibration was performed using microscopically enumerated samples of actinospores to obtain a line fit to $C_{t}$ values from qPCR. Samples contained 11, 16, 55, 59 and 72 actinospores that were washed from a slide with tap water after counting. After the addition of excised and weighted TL strain rainbow trout gill arches, the samples were frozen in distilled water $\left(\mathrm{dH}_{2} \mathrm{O}\right)$ and stored at $-20^{\circ} \mathrm{C}$ until molecular examination.

After thawing, samples were homogenised in $1.5 \mathrm{ml}$ microtubes with a sterile plastic Eppendorf pestle. Microtubes containing homogenate were then filled with $\mathrm{dH}_{2} \mathrm{O}$, mixed by vortexing and centrifuged in a tabletop centrifuge (Eppendorf model 5417R) at full speed $(19300 \times g)$ for $10 \mathrm{~min}$. After the removal of the supernatant, the pellet was re-suspended in $100 \mu \mathrm{l}$ $\mathrm{dH}_{2} \mathrm{O}$. ATL lysis buffer $(400 \mu \mathrm{l})$ and $50 \mu \mathrm{l}$ Proteinase K (20 $\mathrm{mg} \mathrm{ml}^{-1}$; Qiagen) were added and incubated at $55^{\circ} \mathrm{C}$ for $2 \mathrm{~h}$. The solution was then carefully pipetted into a new tube, without the pre-digested gill arches that consisted of cartilage only. Digestion proceeded overnight. The rest of the genomic DNA extraction followed the animal tissue protocol of the Qiagen DNA Mini Kit. Extracted DNA was quantified spectrophoto- metrically and by using parasite-specific PCR with the same primer pair and conditions as for qPCR.

For qPCR, a BioRad MyIQ Single Color Real-Time PCR Detection System (Bio-Rad Laboratories) was applied using the primer pair 811F (5' - TGA ATA AAT CAG AGT GCT CAA AGC - 3') and 937R (5' - TTG GTG CTG TAT GCT GTA ACT G - 3') specific for the 18S rDNA of Myxobolus cerebralis (Cavender et al. 2004). The efficiency of the parasite gene detection was tested in triplicates on a 5 -fold dilution series of genomic DNA (from 100 to $0.8 \mathrm{ng}$ ) that was extracted from a mixture of $158 \mathrm{M}$. cerebralis actinospores and $72 \mathrm{mg}$ trout gill tissue. Every qPCR reaction in a final volume of $25 \mu$ l contained $1 \mu \mathrm{l}$ of genomic DNA, $1 \mu \mathrm{M}$ of each primer, $1 \times \mathrm{SYBR}$ Green Supermix and $\mathrm{ddH}_{2} \mathrm{O}$. After $3 \mathrm{~min}$ of DNA denaturation at $95^{\circ} \mathrm{C}, 40$ cycles were performed at $95^{\circ} \mathrm{C}$ for $30 \mathrm{~s}, 58^{\circ} \mathrm{C}$ for $30 \mathrm{~s}$ and $72^{\circ} \mathrm{C}$ for $30 \mathrm{~s}$. A melting point curve that followed the cycling, starting from $55^{\circ} \mathrm{C}$ and increasing by $0.5^{\circ} \mathrm{C}$ every $30 \mathrm{~s}$ up to $95^{\circ} \mathrm{C}$, was used to detect any non-specific PCR products. The $C_{t}$ value was defined as the point (i.e. number of cycles) at which the fluorescence rose above the background signal.

Statistical methods. To test for normal distribution of the data, the Kolmogorov-Smirnov test was used, while homogeneity of variances was assessed by the Levene test or the Barlett procedure. Data from parasite enumeration were compared as a quotient of the applied specimens between all groups of interest using analysis of variance (ANOVA). Error probability levels were checked by 2 -sample $t$-tests. A multiple $t$-test (Tukey HSD) was used after arcsine square root transformation in the case of values normalised to the maximum of detected stages (difference total of day, DTOD). qPCR data were compared using the Mann-Whitney $U$-Test. Statistical analyses were performed using SPSS and WinSTAT (R. Fitch software).

\section{RESULTS}

\section{Exposure to stained actinospores}

Fluorescent sporoplasms emerging from the endospore (Fig. 1A) could easily be detected on tissues even after penetration of the epithelia (Fig. 1B). Attached endospore units (Fig. 1C) just prior to sporoplasm emission were also visible. Such clear invasion stages could be easily discerned from intact actinospore stages (Fig. 1D), which were excluded although they had obviously attached to the fish surface by polar filament extrusion. Results of the observed fluorescent stages among the 9 replicates are summarised in Table 1. The total amounts of invading parasite stages were not significantly different 

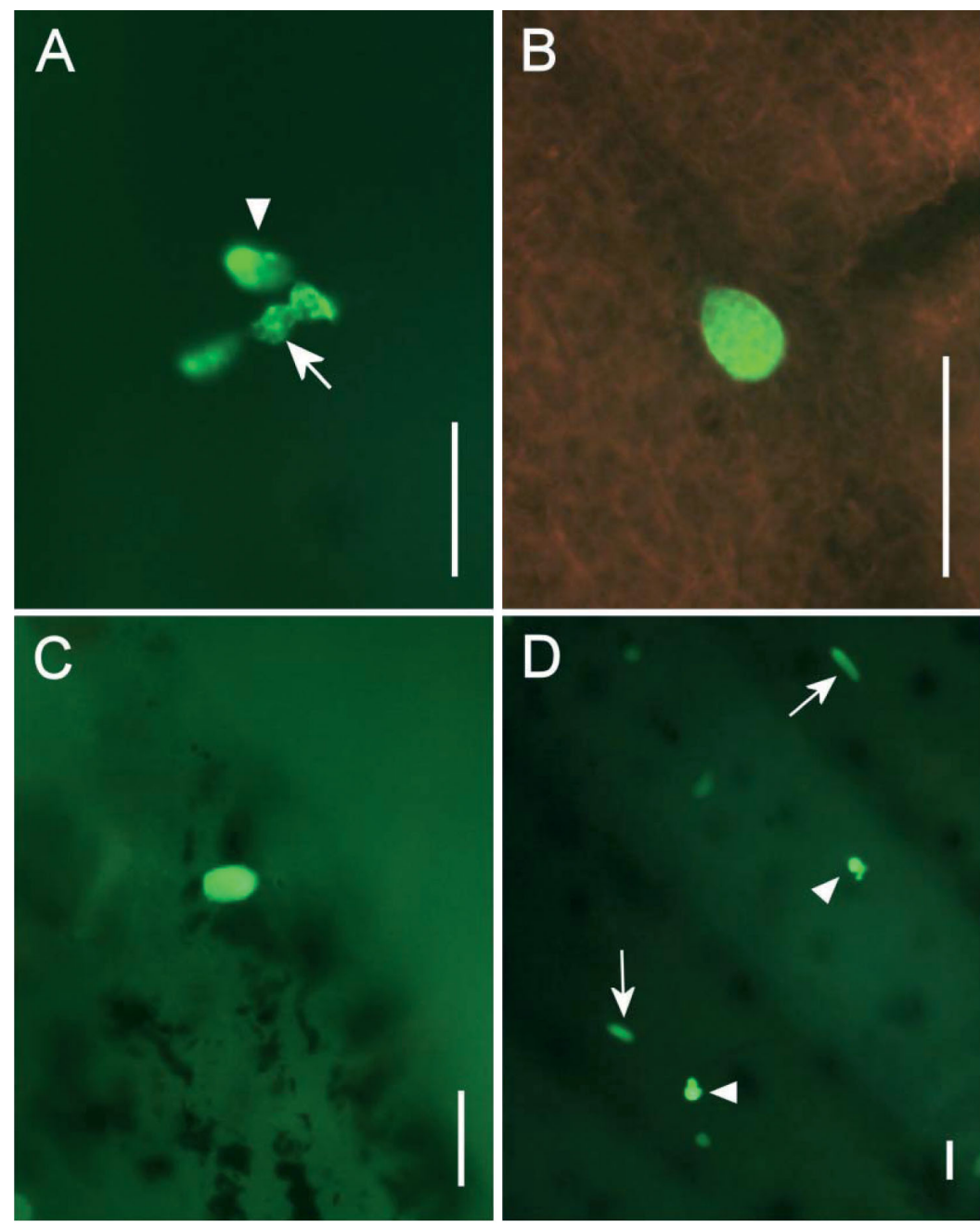

Fig. 1. Myxobolus cerebralis. Fluorescein-diacetate-stained actinospore stages visualised by fluorescence microscopy showing invasion behaviour after 3 min of exposure to fish. (A) Sporoplasm (arrow) emerged from endospore sheath (arrowhead) in mucus scraping of rainbow trout. (B) Sporoplasm penetrated into epidermis of carp caudal fin (partial bright field illumination). (C) Endospore containing sporoplasm attached to caudal fin region of rainbow trout. (D) Attached actinospores (arrows) and sporoplasms emerging from endospore sheath (arrowheads) on carp pectoral fin. Scale bars $=45 \mu \mathrm{m}$

between exposed fish species $(\mathrm{p}=0.42, F=0.89, \mathrm{df}=2$, ANOVA). Surprisingly, H strain rainbow trout showed a higher total amount of invading stages than the TL strain specimens (Table $1 ; \mathrm{p}=0.25$, $t$-test). Carp provoked as many invasion attempts as TL rainbow trout ( $p=0.89, t$-test). Numbers of invading sporoplasms were highest for excised gill arches in all sampled fish, whereas the fewest individuals were detected on caudal fins. Relatively high numbers of parasite stages on the latter were obtained in $\mathrm{H}$ strain rainbow trout, which was almost entirely due to only 2 replicates. A few parasite stages were detected in 1 replicate on control trout exposed to stained filtrate on the gill and pectoral fin, which obviously had been flushed into the spore filtrate that was used for exposure of controls. The agar mimic fish had a total of only 2 parasites attached to the lateral cut, of which none was fully emitted from the endospore.

As spore reactivity rate may vary between different spore isolates (and therefore between days of conduction of each replicate), an alternative value was computed to normalise the data relative to the total reaction rate of the given isolate of a day's parasite samples (Table 1). It was calculated as the mean difference between total emerged sporoplasms detected on the exposure date and those found on the respective sample (DTOD). As this mean difference becomes lower, this group deviates less from the maximal invasion rate, while the difference in parasite load should become more apparent. However, even after this normalisation procedure, differences between groups remained non-significant $(p=0.15)$.

\section{Preincubation trial}

To test the potency of carp to remove actinospores from water bodies by exploiting their putative unspecific host invasion behaviour, we compared parasite load after myxospore development in individual rainbow trout. For this purpose, TL strain rainbow trout were exposed to Myxobolus cerebralis actinospores in actinospore-containing water with and without prior addition of 1 carp per infection solution. There was no difference in fish size between the 2 groups at $109 \mathrm{~d}$ post exposure (data not shown). Cranial deformations were visible in all specimens of the group without carp addition, while only 3 out of 9 ind. showed symptoms in the group in which carp were added before infection. Mean spore counts from volume equilibrated samples of digested head skeletal elements in four $0.04 \mathrm{~mm}^{2}$ Bürker chamber squares $(\mathrm{n}=20)$ were $3.88( \pm 0.54$ SEM) myxospores in fish without and $1.74( \pm 0.36 \mathrm{SEM})$ with carp addition to the infection solution. This reduction to half the infection intensity by preincubation with carp was highly significant $(\mathrm{p}<0.005, F=10.7$, ANOVA). 
Table 1. Myxobolus cerebralis. Mean numbers of emerged sporoplasms from triactinomyxon spores on fish epithelia (or control) after exposure to 8000 actinospores for 3 min (9 fish replicates). SEM: standard error of the mean; \% of total: mean percentage of emerged sporoplasms on tissue of total mean sum; DTOD: difference total of day, i.e. mean difference between total emerged sporoplasms detected on the exposure date and those found on the respective sample; TL: Troutlodge strain; H: Hofer strain

\begin{tabular}{|c|c|c|c|}
\hline Tissue & Mean & SEM & $\%$ of total \\
\hline \multicolumn{4}{|c|}{ Rainbow trout $(\mathrm{H})$} \\
\hline Gills & 24.0 & 2.4 & 61.9 \\
\hline Pectoral fin & 8.6 & 3.0 & 22.1 \\
\hline Tailfin & 3.7 & 2.4 & 9.5 \\
\hline Body mucus & 2.6 & 0.9 & 6.6 \\
\hline Total & 38.8 & 6.0 & \\
\hline DTOD & 64.4 & 5.3 & \\
\hline \multicolumn{4}{|c|}{ Rainbow trout (TL) } \\
\hline Gills & 23.2 & 3.5 & 76.3 \\
\hline Pectoral fin & 4.7 & 1.0 & 15.3 \\
\hline Tailfin & 1.0 & 0.3 & 3.3 \\
\hline Body mucus & 1.6 & 0.4 & 5.11 \\
\hline Total & 30.4 & 3.6 & \\
\hline DTOD & 72.8 & 9.9 & \\
\hline \multicolumn{4}{|l|}{ Carp } \\
\hline Gills & 21.4 & 4.5 & 68.7 \\
\hline Pectoral fin & 3.8 & 1.7 & 12.1 \\
\hline Tailfin & 2.3 & 0.9 & 7.4 \\
\hline Body mucus & 3.7 & 1.3 & 11.7 \\
\hline Total & 31.2 & 4.6 & \\
\hline DTOD & 72.0 & 6.8 & \\
\hline \multicolumn{4}{|c|}{ Rainbow trout control (TL) } \\
\hline Gills & 0.56 & 5.8 & 71.4 \\
\hline Pectoral fin & 0.22 & 3.7 & 28.6 \\
\hline Tailfin & 0 & - & - \\
\hline Body mucus & 0 & - & - \\
\hline Total & 0.8 & 0.6 & \\
\hline DTOD & 102.4 & 9.8 & \\
\hline \multicolumn{4}{|l|}{ Agar control } \\
\hline Body & 0.2 & 0.1 & 100 \\
\hline Tail & 0 & - & - \\
\hline Total & 0.2 & 0.1 & \\
\hline DTOD & 103.0 & 10.2 & \\
\hline
\end{tabular}

\section{Quantitative real-time PCR}

Invading Myxobolus cerebralis actinosporean stages were additionally quantified by a qPCR assay designed for $M$. cerebralis that specifically amplified a $140 \mathrm{bp}$ long fragment of $18 \mathrm{~S}$ rDNA with high efficiency. The necessary tool for approximate enumeration of actinospores was achieved by creating a linear calibration curve from a series of samples with a known number of actinospores (Fig. 2). The number of invading sporoplasms could thus be determined from $C_{t}$ values of the qPCR setup by the equation

$$
N_{s}=-1 / 0.063 \times\left(C_{t s}-28.637\right)
$$

where $N_{S}$ is the number of calculated stages of the sample, and $C_{t s}$ is the $C_{t}$ value of the sample measured by qPCR.

Absolute numbers of invading parasites obtained by visual detection in carp and trout gills were verified by molecular detection methods as well. According to computation using the mean $C_{t}$ values, 26.2 stages were detected in trout gills; calculation for carp gills gave 29.9 parasites. Furthermore, putative differences in reaction potency between stained and unstained actinospores in gill samples of exposed rainbow trout needed to be excluded. The calculated mean number of unstained stages in gill samples was $61.5( \pm 11.4, \mathrm{SE})$ and an amount of $57.6( \pm 4.3)$ stages was detected with the stained parasites $(n=8)$. The difference was not significant ( $p=0.56, Z=-0.58$, Mann-Whitney $U$-test). Therefore, FDA staining does not impair the ability of actinospores to invade host tissue.

\section{DISCUSSION}

We showed and experimentally evaluated actionsporean invasion behaviour of Myxobolus cerebralis on live fish tissue for the first time. Our key findings are: (1) $M$. cerebralis actinospores cannot discern host fish species and strains; (2) gills are the preferred site of entry; and (3) non-susceptible carp are indeed capable of significantly lowering infection intensity when used as decoy fish. We also observed that a comparable (in our case even higher) number of actinospores attached and sought entry into less susceptible Hofer strain trout. This result is important for the interpretation of infection experiments comparing this far less susceptible strain to other rainbow trout strains. It cannot be fully excluded that carp may in fact serve as cryptic hosts for $M$. cerebralis, although this probability appears minute and no report on such an infection in carp is known to us. In histological examinations by El-Matbouli et al. (1999), exposed carp did not show any developmental stages or spores. In our own trials (authors' unpubl. data), carp were repeatedly found to be free of penetrated sporoplasms after exposure and remained PCR-negative for $M$. cerebralis while rainbow trout became heavily infected. Therefore we can justify considering carp to be non-susceptible to $M$. cerebralis. In the present study, we assured that host invasion attempts were measured as a whole, not just accidental attachment by polar filament discharge, because only emerged sporoplasms were considered. The consistently low attachment rates despite exposure to relatively high densities of actinospores indicate the coincidental fashion and time-dependency of actinosporean invasion. The exposure time of $3 \mathrm{~min}$ was rather short to ensure an infection with realistic 


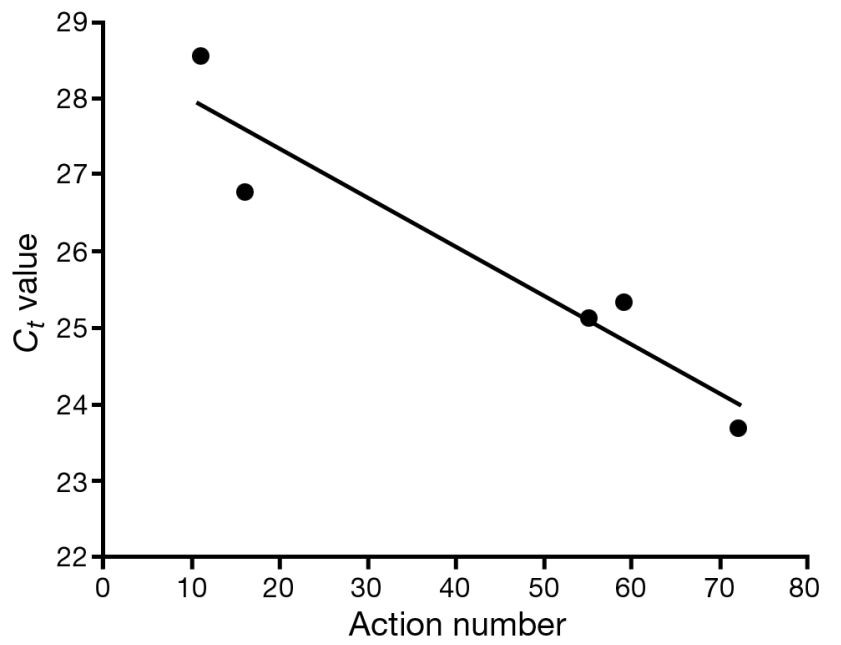

Fig. 2. Myxobolus cerebralis. Calibration line for numbers of actinospores in rainbow trout gill tissue and respective $C_{t}$ values as measured by qPCR. Equation: $y=-0.0639 x+28.637$

numbers of parasites, while overexposure could have masked specific differences in the reactions of the parasite. As shown by qPCR detection, the staining procedure did not affect the ability of spores to attach onto the fish host surface. Although FDA may cause spontaneous discharge of polar capsules (Kallert \& El-Matbouli 2008), it was not possible to measure whether a greater number of unstained actinospores would attempt penetration after anchorage to the host. Differences in absolute numbers of parasites found on rainbow trout gills in the different analyses (despite using the same spore concentrations) highlight the importance of using the same parasite aliquots for comparison of all samples. Reactivity of actinospores may be influenced by several factors, because some isolates were not reactive at all, even to host mucus homogenate (D. M. Kallert pers. obs., data not shown). One explanation for this is the production of polar capsules smaller than usual in size and aberrant morphology often observed in a certain fraction of actinospores of M. cerebralis. These actinospores with nonfunctional polar capsules may originate from single oligochaete hosts that are less compatible for the parasite or single parasite clones with deleterious mutations.

A single actinospore bears several hundred copies of 18S rDNA and, thus, greater deviation in measurement must be expected for smaller spore numbers, whereas for larger spore amounts, deviation is relatively smaller. The calibration curve of qPCR with enumerated actinospores likewise could show non-linear characteristics when smaller actinospore numbers are to be detected. When the curve regression was transformed to fit a logarithmic course (described by the equation $\left.C_{t s}=-2.044 \times \ln \left[N_{s}\right]+33.083\right)$, the estimated number of parasite stages reduced, but values remained similar (i.e. not significantly different) (20.0 and 22.6 stages for trout and carp, respectively). Actinospore numbers of carp and trout gills estimated by qPCR gave similar values, although only 3 samples per species were used for the calculation. It is also expected that invading stages show higher $C_{t}$ values than do intact actinospores, as some parts of the spore body (i.e. valve cells and polar capsule cells) are missing after sporoplasm emergence. Therefore, the calculated spore numbers should in fact be corrected slightly upward. Nevertheless, according to our qPCR results, more parasite stages were found attempting to invade carp than highly susceptible TL strain rainbow trout. This affirmed the result from visual analysis of fluorescently stained parasites and intuitively demonstrates the lack of host specificity in Myxobolus cerebralis host attachment and invasion. The results of the preincubation experiment repeatedly demonstrated the non-specific reactions of $M$. cerebralis actinospores with carp. Fish other than salmonids may therefore be considered biological aids that trap actinospores and remove them from the water body. A highly diverse fish fauna in endemic water, thus, could help to reduce fry mortality due to whirling disease by lowering the parasite load.

Differences in susceptibility among salmonid species toward Myxobolus cerebralis are thought to arise from immune responses occurring against late parasite developmental stages (Baerwald et al. 2008). This seems not to be the case for non-susceptible host species, which do not allow the parasite to develop at all. In a study by El-Matbouli et al. (1999), no penetrated stages were found in various non-susceptible fishes; however, 1 guppy exposed to Sphaerospora sp. showed several stages in the epidermis. Yokoyama et al. (2006) confirmed their earlier findings that the carpinfecting myxozoan Thelohanellus hovorkai rarely penetrated salmonids and goldfish. When goldfish were exposed to actinospores of the salmonid-specific myxozoan Mxyobolus arcticus, only a few penetrated sporoplasms were observed. These facts along with our results support the theory that myxozoans are potentially capable of entering a variety of fish species, but the majority is hindered during initial invasion of non-susceptible species. The results of this work also support the hypothesis that sporoplasm penetration is inhibited in non-suitable fish hosts. What remains unclear is the mechanism of this early inhibition on the wrong host. One explanation could be that the sporoplasm is intercepted by mucus-derived immune factors to which the parasite is not adapted. Parasite immune evasion is ubiquitous (Schmid-Hempel 2008), and in the case of $M$. cerebralis, resistance by immune masking may be inadequate to protect from, for example, cyprinid-specific defence molecule isoforms such as 
lectins, antimicrobial peptides, complement or lysozyme. Another barrier may be the inability of the parasite to establish salmonid-specific cell-cell recognition junctions required for initiation of the penetration behaviour. In both cases, osmotic stress is a lethal threat to primary cells that are not protected by the endosporean sheath. All myxozoan sporoplasms known to us stop their movement after $10 \mathrm{~min}$ in aqueous solutions (authors' pers. obs.).

Results of differential reaction rates in actinospores indicate altering invasion mechanisms, which may have developed as environmental adaptations, e.g. by sensitivity adjustment to the stimuli profile of the host mucus (e.g. compare high protein bream mucus to that of trout) or physical conditions. According to experiments of Yokoyama et al. (2006), Thelohanellus hovorkai is able to distinguish its susceptible fish host from non-susceptible host species. This was the first case of host-specific invasion reactions demonstrated for a myxosporean. However, in our own observations, carp mucus often elicits far higher sporoplasm release rates in salmonid-specific actinospores than trout mucus of the same concentration. In addition, response-inducing activity of carp mucus seems to be more temperature stable than that of trout mucus. The low chemoresponse of $T$. hovorkai to fish mucus and its slow reaction, as well as the lack of overall reactivity of Myxobolus parviformis (Kallert et al. 2007), indicate difficulty to induce in vitro filament discharge or sporoplasm release in some species. A reason for this may be that actinospores specific for bottom feeding fish may be generally less sensitive to chemical cues as they may predominantly infect fish through oral uptake. On the other hand, it must be noted that most older reports lack important methodical premises such as substrate normalisation (e.g. to dry weight), $\mathrm{pH}$ buffering, mechanical stimulation, proper sample preparation, buffered controls, blinded protocols, replicate conduction and statistical evaluation. In addition, the content of host stimuli in mucus samples even of the same fish varies considerably among isolates (authors' unpubl. data).

How can the absence of a host-specific recognition mechanism of myxozoan actinospores be explained? To date, we know very little about the mechanisms determining myxozoan host specificity in fish. The most common seems to be specificity (ability to develop mature functional myxospores) to a teleost group or family, with the exception of some myxozoan species that show great species and tissue specificity. It was recognised early that parasite host specificity is neither an absolute nor a unilateral adaptation and is conditioned mainly by the ecological environment of the host where the parasite must complete its life cycle (Shulman 1958). Parasite-derived host speci- ficity by differential recognition is of greater evolutionary benefit only when mating has to be accomplished in a narrow host range and is found mainly in parasites with active host-finding (e.g. the fish-parasitic monogenean Entobdella solea). Otherwise, elevated recognition specificity has a negative long-term effect as the likelihood to invade new hosts is hampered (Dick \& Patterson 2007). Eventually, this is reflected by the great amount of myxozoan species that may not have evolved if transmission stages would act highly host specific. Apparently, passive host finding in actinospores is facilitated as water currents keep the transmission stages in constant motion, although not directed towards potential hosts. Furthermore, as mating by Myxobolus cerebralis in fish is achieved by autogamy, high specificity of host recognition is of no use for parasite reproduction. The effect of specific recognition on life cycle and reproduction is probably outweighed by the benefits of a rapid response upon contact with any fish to increase likelihood of successful host entrance. We suggest that in the majority of myxozoans, the host and its environment did not put sufficient selective pressure on actinospores to be more than fish-specific. There may be selective pressure to avoid this costly adaptation in these r-strategy transmission stages. Specificity for fish in contrast to other aquatic organisms, as previously suggested (Kallert et al. 2005), is therefore sufficient for closing the cycle, at least in M. cerebralis.

Acknowledgements. Thanks are due to Sho Shirakashi for critical reading of the manuscript. This work was supported by a grant from the Deutsche Forschungsgemeinschaft (Grant EL 174/2-1).

\section{LITERATURE CITED}

Baerwald MR, Welsh AB, Hedrick RP, May B (2008) Discovery of genes implicated in whirling disease infection and resistance in rainbow trout using genome-wide expression profiling. BMC Genomics 24:9-37

Cavender WP, Wood JS, Powell MS, Overturf K, Cain KD (2004) Real-time quantitative polymerase chain reaction (QPCR) to identify Myxobolus cerebralis in rainbow trout Oncorhynchus mykiss. Dis Aquat Org 60:205-213

> Dick CW, Patterson BD (2007) Against all odds: explaining high host specificity in dispersal-prone parasites. Int J Parasitol 37:871-876

El-Matbouli M, Hoffmann RW, Schoel H, McDowell TS, Hedrick RP (1999) Whirling disease: host specificity and interaction between the actinosporean stage of Myxobolus cerebralis and rainbow trout Oncorhynchus mykiss. Dis Aquat Org 35:1-12

Gilbert MA, Granath WO (2003) Whirling disease of salmonid fish: life cycle, biology, and disease. J Parasitol 89:658-667

Hedrick RP, El-Matbouli M (2002) Recent advances with taxonomy, life cycle, and development of Myxobolus cerebralis in the fish and oligochaete hosts. Am Fish Soc Symp 29:45-53 
Kallert DM, El-Matbouli M (2008) Differences in viability and reactivity of actinospores of three myxozoan species upon ageing. Folia Parasitol (Praha) 55:105-110

Kallert DM, El-Matbouli M, Haas W (2005) Polar filament discharge of Myxobolus cerebralis actinospores is triggered by combined non-specific mechanical and chemical cues. Parasitology 131:609-616

Kallert DM, Ponader S, Eszterbauer E, El-Matbouli M, Haas W (2007) Myxozoan transmission via actinospores: new insights into mechanisms and adaptations for host invasion. Parasitology 30:1741-1750

Kelley GO, Adkison MA, Zagmutt-Vergara FJ, Leutenegger $\mathrm{CM}$ and others (2006) Evaluation of quantitative real-time PCR for rapid assessments of the exposure of sentinel fish to Myxobolus cerebralis. Parasitol Res 99:328-335

Lorz HV, Amandi A (1994) VI. Whirling disease of salmonids. In: Thoesen JC (ed) Suggested procedures for the detection and identification of certain finfish and shellfish pathogens, 4th edn. Am Fish Soc, Fish Health Section, Bethesda, MD, p 1-7

Markiw ME (1992) Experimentally induced whirling disease II. Determination of longevity of the infective triactinomyxon stage of Myxobolus cerebralis by vital staining. J Aquat Anim Health 4:44-47

McGeorge J, Sommerville C, Wootten R (1997) Studies of actinosporean myxozoan stages parasitic in oligochaetes from the sediments of a hatchery where Atlantic salmon har-

Editorial responsibility: Alex Hyatt,

Geelong, Victoria, Australia bour Sphaerospora truttae infection. Dis Aquat Org 30: $107-119$

Özer A, Wootten R (2002) Biological characteristics of some actinosporeans. J Nat Hist 36:2199-2209

Schmid-Hempel P (2008) Parasite immune evasion: a momentous molecular war. Trends Ecol Evol 23:318-326

Shulman SS (1958) Specificity of fish parasites. In: Dogiel VA, Petrushevski GK, Polyanski YI (eds) Parasitology of fishes. Oliver \& Boyd, Edinburgh, p 104-116

Xiao C, Desser SS (2000) The longevity of actinosporean spores from oligochaetes of Lake Sasajewun, Algonquin Park, Ontario, and their reaction to fish mucus. J Parasitol 86:193-195

Yokoyama H, Urawa S (1997) Fluorescent labelling of actinospores for determining the portals of entry into fish. Dis Aquat Org 30:165-169

Yokoyama H, Ogawa K, Wakabayashi H (1993) Some biological characteristics of actinosporeans from the oligochaete Branchiura sowerbyi. Dis Aquat Org 17: $223-228$

Yokoyama H, Ogawa K, Wakabayashi H (1995) Chemoresponse of actinosporean spores of Myxobolus cultus to skin mucus of goldfish Carassius auratus. Dis Aquat Org 21:7-11

> Yokoyama H, Kim HJ, Urawa S (2006) Differences in host selection of two myxosporeans, Myxobolus arcticus and Thelohanellus hovorkai. J Parasitol 92:725-729

Submitted: October 17, 2008; Accepted: January 16, 2009

Proofs received from author(s): March 17, 2009 